\title{
EQUIPARAÇÃO SALARIAL ENTRE EMPREGADOS DE UM MESMO GRUPO ECONÔMICO
}

\author{
Elaine Cristina Saraiva Bentivoglio* \\ Rogério Gonçalves de Oliveira ${ }^{* * *}$
}

RESUMO

Este artigo tem por objetivo analisar a possibilidade, ou não, da aplicação do instituto da equiparação salarial entre empregados de empresas integrantes de um mesmo grupo econômico. Inicialmente serão analisados os princípios da proteção e da primazia da realidade. Posteriormente será estudado o instituto da equiparação salarial e os requisitos para sua aplicação: identidade de função exercida, trabalho de igual valor, identidade de empregador, identidade de localidade e simultaneidade na prestação de serviços. O requisito mesmo empregador terá uma análise mais detalhada, onde será estudada a formação do grupo econômico para fins trabalhistas e suas principais consequências, tais como a hierarquização e a solidariedade passiva/ativa existente entre empresas de um mesmo grupo econômico. O trabalho será finalizado com a verificação da aplicação da equiparação salarial entre empregados de empresas integrantes de um mesmo grupo econômico, apresentando os pontos mais importantes destacados pela doutrina e pela atual jurisprudência sobre o tema.

Palavras-chave: equiparação salarial. grupo econômico. empregador.

\footnotetext{
* Mestre em Direito pela Universidade Metropolitana de Santos - UNIMES. Advogada. Professora Universitária e Orientadora do Escritório de Assistência Judiciária do Curso de Direito da Universidade Metodista de São Paulo.

** Advogado. Graduado em Direito pela Universidade Metodista de São Paulo. 


\section{ABSTRACT}

This article aims to examine the possibility, or not, the application of the provisions of salary equality between employees of member companies of the same economic group. Initially the principles of protection and the primacy of reality will be analyzed. After that will be studied the provisions of salary equality and the requirements for their application: Identity job function, work of equal value, employer identity, location identity and simultaneity in the provision of services. The same employer requirement will have a more detailed analysis, which will study the formation of the economic group for labor purposes and its main consequences, such as tiering and passive solidarity / active existing between companies of the same economic group. The work will be completed with the verification of the implementation of equal pay among employees of member companies of the same economic group, with the most important points highlighted by the doctrine and the current jurisprudence on the subject.

Keywords: equal pay . economic group. employer.

\section{INTRODUÇÃO}

O objetivo deste artigo é fazer uma análise do instituto da equiparação salarial e a possibilidade, ou não, da sua aplicação entre empregados de empresas distintas, porém integrantes de um mesmo grupo econômico.

Com o avanço da tecnologia, da globalização, da evolução dos meios de produção, da busca da maximização do lucro e produtividade, com a consequente diminuição dos custos e da manutenção da posição no mercado, fez nascer uma nova figura de empregador: os grupos econômicos. Um empregador que antes, apenas, produzia a matéria prima, hoje, fabrica o produto, vende e até pratica atividades de exportação.

Diante deste novo cenário, por vezes, uma empresa pertencente a um grupo econômico é surpreendida com demandas judiciais nas quais ex-empregados pleiteiam equiparação salarial com paradigma contratado por outra empresa 
integrante do grupo, ficando na dúvida se é ou não legal essa equiparação, uma vez que os trabalhadores foram contratados por empresas distintas, embora pertencentes ao mesmo grupo econômico. A questão não comporta entendimento pacífico, quer no âmbito doutrinário, quer no âmbito judicial.

A criação do grupo econômico pela ordem justrabalhista foi assegurar maior garantia aos créditos trabalhistas em contexto socioeconômico de crescente despersonalização do empregador e pulverização dos empreendimentos empresariais em numerosas organizações juridicamente autônomas.

Para solucionar a dúvida de equiparação salarial entre empregados de empresas integrantes de um mesmo grupo econômico o presente artigo enfrentará uma análise mais profunda acerca do critério "mesmo empregador".

Faremos uma revisão bibliográfica, doutrinaria e jurisprudencial sobre os principais institutos envolvidos: os principios do direito do trabalho, a diferenciação do conceito de salário e remuneração, o tema equiparação salarial e seus requisitos para sua caracterização, o conceito de empregador e a caracterização do grupo econômico de empresas, o conceito de empregador único e a sua solidariedade.

A pretensão não é esgotar o assunto que envolve o tema equiparação salarial nos grupos econômicos, tendo em vista as inúmeras diversidades dos conceitos envolvidos, mas apresentar uma conclusão a respeito da possibilidade, ou não, da aplicação da equiparação salarial entre empregos de empresas integrantes de um grupo econômico trabalhista.

\section{PRINCÍPIOS}

No presente capítulo serão abordados os princípios que estão intimamente ligados à proteção do salário e da equiparação salarial, bem como a apresentação de jurisprudência atual a respeito do tema. 


\subsection{PRINCÍPIOS NO DIREITO DO TRABALHO}

O estudo de todo o ramo do direito é orientado por princípios que fundamentam suas regras e aplicação, neste capítulo será abordado a importância dos princípios para o direito do trabalho.

Delgado (2014, p. 184) nos ensina que "a palavra princípio traduz, na linguagem corrente, a ideia de começo, início, e nesta linha, o primeiro momento da existência de algo ou de uma ação ou processo".

Para Nascimento (2011) o estudo dos principios deve ser feito em conjunto com as normas da CLT, e representam um conjunto de direitos conferidos ao trabalhador como meio de dar equilíbrio entre os sujeitos do contrato de trabalho, diante da natural desigualdade que os separa, e favorece uma das partes do vínculo jurídico, a patronal.

Assim, os princípios para o direito do trabalho atuam como garantidor de direitos ao trabalhador, equilibram a desigualdade existente em uma relação de trabalho entre empregador e empregado. Coíbem, também, abusos por parte daquele que dirige, orienta a prestação de serviços: o empregador. Para o tema equiparação salarial os princípios exercem grande influência, pois garantem que a igualdade dos salários para trabalhos iguais, prestados ao mesmo empregador e na mesma localidade, como veremos a seguir.

\subsection{PRINCÍPIO DA PROTEÇÃO}

O princípio da proteção é base de estudo do direito do trabalho e dos demais princípios que norteiam o direito do trabalho.

Nos ensinamentos de Plá Rodriguez (2000) o princípio da proteção representa o critério fundamental que orienta o direito do trabalho, pois este estabelece um amparo preferencial ao trabalhador e o seu fundamento está ligado à própria razão de ser do direito do trabalho, que surgiu como consequência de que a liberdade de contrato entre pessoas com poder e 
capacidade econômica desiguais conduzia a diferentes formas de exploração. O direito do trabalho surgiu como compensação da desigualdade existente em um contrato de trabalho.

Nas palavras de Couture (1944) apud Plá Rodriguez (2000) para corrigir desigualdades é preciso criar outras desigualdades.

Ainda segundo o autor o princípio da proteção se manifesta em três dimensões distintas, a saber: princípio in dubio pro operario (in dubio pro misero), princípio da norma mais favorável e princípio da condição mais benéfica.

\subsubsection{Principio in dubio pro operario (in dubio pro misero)}

Este princípio, segundo Plá Rodrigues (2000), será utilizado pelo juiz ou pelo interprete para escolher, entre vários sentidos possiveis de uma norma, aquele que seja mais favorável ao trabalhador.

Uma determinada norma trabalhista poderá trazer sentido dúbio, ou seja, comportando várias interpretações. Para Leone (2014) aplicando o princípio em estudo, o interprete deverá optar, entre duas ou mais interpretações possíveis, pela mais favorável ao empregado.

Assim, o princípio in dubio pro operario pressupõe a existência de duas interpretações para a mesma norma, colocando em dúvida a aplicação do direito ao caso concreto, neste caso o interprete, o juiz, deverá sempre considerar a interpretação que beneficie o trabalhador, tendo em vista o princípio da proteção e da hipossuficiência do empregado.

\subsubsection{Princípio da norma mais favorável}

A regra da norma, para Plá Rodriguez (2000), consiste no caso de existir mais de uma norma aplicável, deve-se optar por aquela que seja mais favorável, ainda que não corresponda aos critérios clássicos de hierarquia das normas.

No direito comum, é adotado o princípio do racionalismo dogmático ou normativismo jurídico de Hans Kelsen, também 
conhecido como princípio da supremacia da Constituição ou da compatibilidade vertical. Este princípio determina que toda a norma inferior deverá respeitar, ser compativel e encontrar seu fundamento de validade na norma superior, estando no ápice da pirâmide a Constituição Federal de 1988. Trata-se de um critério rígido, inflexível, com controle de constitucionalidade afirma Leone (2014).

Porém em contrapartida, no direito do trabalho, é adotado critério mais flexível e variável. Assim, no ápice da pirâmide aplicamos o princípio da norma mais favorável, de forma que será aplicada a norma mais favorável ao trabalhador independentemente de sua posição na escala hierárquica.

Enquanto no princípio in dubio pro operario existe dúvida em relação a interpretação que deve-se dar a uma norma, no princípio da norma mais favorável existe dúvida em que norma aplicar ao caso concreto. Neste caso com base no princípio da proteção deve-se aplicar aquela for mais benéfica ao empregado, sem considerar sua posição hierárquica no ordenamento jurídico.

\subsubsection{Princípio da condição mais benéfica}

Tal princípio orienta que uma nova norma trabalhista nunca deve servir para diminuir as condições mais favoráveis em que se encontra um trabalhador, conforme ensina Plá Rodriguez (2000).

Também conhecido, segundo Leone (2014), como princípio da cláusula mais vantajosa, esclarece que as condições mais benéficas previstas no contrato de trabalho ou no regulamento da empresa prevalecerão e serão incorporadas por definitivo ao contrato de trabalho, não podendo ser retiradas ou reduzidas no curso da relação laboral. Assim, a vigência de diploma normativo menos protetivo não atingira os contratos de trabalho em curso, mas apenas os novos contratos.

A aplicação da regra da condição mais benéfica pressu- 
põe a existência de uma situação concreta, anteriormente reconhecida. Plá Rodriguez (2000) determina que ela deva ser respeitada, na medida em que seja mais favorável ao trabalhador que a nova norma aplicável.

A soma dos princípios in dubio pro operario, norma mais favorável e condição mais benéfica é o resultado do princípio da proteção, princípio que representa o alicerce do direito do trabalho e que orienta a aplicação do instituto da equiparação salarial. Através do princípio da proteção o julgador aplicará todos os requisitos da equiparação salarial ao caso concreto, visando proteger o empregado que representa a parte mais frágil da relação de trabalho e da produção de provas para tal pleito.

\subsection{PRINCÍPIO DA PRIMAZIA DA REALIDADE}

Outro importante princípio para o direito do trabalho e para o instituto da equiparação salarial é o princípio da primazia da realidade.

Plá Rodriguez (2000, p. 339) ensina que "o princípio da primazia da realidade significa que, em caso de discordância entre o que ocorre na prática e o que emerge de documentos e acordos, deve-se dar preferência ao primeiro, por isto é, ao que sucede no terreno dos fatos".

Deveali 1947 apud Plá Rodriguez 2000 sustenta que a relação de trabalho que representa o fato jurídico, deve prevalecer sobre o contrato de trabalho, evidenciando o contrato realidade da prestação de serviço. Para Delgado (2014) e Plá Rodriguez (2000) é comum a utilização do termo contrato realidade para se referir ao princípio da primazia da realidade.

O significado do princípio da primazia da realidade, para Plá Rodriguez (2000) é o da primazia dos fatos sobre as formas, as formalidades ou as aparências.

Assim, no direito do trabalho o que importa é o que ocorre na prática, mais do que aquilo que as partes tenham pactuado de forma mais ou menos solene, ou expressa, ou 
aquilo que esteja presente em documentos, contratos, formulários e instrumentos de controle.

O princípio da primazia da realidade se traduz na preferência da verdade dos fatos sobre a verdade documental. Isso significa que pouco é importante o que foi lançado no documento formal, ou físico, o que realmente tem importância para o direito do trabalho é a realidade dos fatos, as ações que na prática são executadas. Grandiosa importância tem tal princípio para o instituto da equiparação salarial, por exemplo: pouco importa se empregados têm ou não a mesma nomenclatura de cargo, o que realmente tem importância é a execução das atividades, se as tarefas executas são iguais, deverão ser também iguais, pelo princípio da primazia da realidade, os salários dos empregados.

\section{EQUIPARAÇÃO SALARIAL}

Na Constituição de 1988 o tema equiparação salarial encontra amparo legal nos artigos $3^{\circ}$, III e IV, $7^{\circ}$, XXX e XXXII, que consagrou que a igualdade deve existir não só em razão dos salários, mas também em relação a funções e critérios de admissão por motivo de sexo, idade, cor ou estado civil. O tema também é tratado na CLT, em seus artigos $5^{\circ}$ e 461, além da Súmula 6 do Tribunal Superior do Trabalho.

Pereira (2014, p. 239) afirma que, “a equiparação é um dos institutos jurídicos mais importantes sobre salário”. O autor defende que o instituto está fundamentado no princípio da igualdade, isonomia ou paridade de armas e que parte da premissa básica que todo aquele que exerce a mesma função tem direito de receber o mesmo salário.

\subsection{SALÁRIO E REMUNERAÇÃO: DISTINÇÕES}

Para a equiparação salarial é muito importante diferenciar remuneração de salário, pois a equiparação salarial, como o próprio nome diz está destinada tão somente aos salários dos empregados e não à remuneração. 


\section{EQUIPARAÇÃO SALARIAL ENTRE EMPREGADOS \\ DE UM MESMO GRUPO ECONÔMICO}

Leone (2014) nos adverte sobre o cuidado que devemos ter para não confundir remuneração e salário. Para o autor a diferença é clara na leitura do artigo 457, caput, da CLT, a seguir:

Art. 457 - Compreendem-se na remuneração do empregado, para todos os efeitos legais, além do salário devido e pago diretamente pelo empregador, como contraprestação do serviço, as gorjetas que receber. (Redação dada pela Lei $\mathrm{n}^{\circ} 1.999$, de 1.10.1953)

Delgado (2014) e Martins Filho (2007) definem salário como o conjunto de parcelas contraprestativas pagas pelo empregador em função do contrato de trabalho. Trata-se de um complexo de parcelas e não de uma única verba. Tem caráter contraprestativo.

A remuneração ao contrário do salário é, segundo Martins Filho (2007), a soma do salário com outras vantagens percebidas, em decorrência do contrato (ex.: salário-base + gorjetas); para as demais espécies de trabalhador, é a contraprestação do serviço.

A equiparação salarial está destinada a salários e não a remuneração. Salário é a contraprestação devida ao empregado pela prestação de serviços, em decorrência do contrato de trabalho. Já a remuneração é a soma do salário, contratualmente estipulado, com outras vantagens percebidas na vigência do contrato de trabalho, como horas extras, adicional noturno, adicional de periculosidade, insalubridade, comissões, percentagens, gratificações, diárias para viagens, entre outras. Todas estas vantagens não são base para a equiparação salarial, mas somente o salário contratual.

\subsection{REQUISITOS DA EQUIPARAÇÃO SALARIAL}

O pedido de equiparação salarial deve estar fundamentado em requisitos que devem obrigatoriamente ser preenchidos, tais requisitos são elencados pela Lei e pela jurisprudência. 
Os requisitos e pressupostos da equiparação salarial, nos ensinamentos de Filho (2007), encontram-se elencados no artigo 461 da CLT e seus parágrafos e na Súmula $n^{\circ} 6$ do Tribunal Superior do Trabalho - TST e seus incisos, que consolidaram toda a jurisprudência sobre a matéria.

São os requisitos da equiparação salarial construídos pela comparação entre situações empregatícias vivenciadas por equiparando e paradigma, a saber: identidade de função exercida, trabalho de igual valor, identidade de empregador, identidade de localidade e simultaneidade na prestação de serviço.

\subsubsection{Identidade de Empregador}

Requisito importantíssimo e o centro dos estudos deste artigo é a identidade de empregador.

Martinez (2012) esclarece que tal requisito diz respeito à limitação do pedido de equiparação salarial. Paradigma precisa ser ou ter sido colega de trabalho do equiparando, necessariamente na mesma empresa, precisa ter convivido com ele no ambiente laboral. O autor ainda afirma que não é possivel a equiparação salarial entre trabalhadores de empresas diferentes.

Segundo Martins (2015, p. 349) “o trabalho realizado pelo equiparando e pelo paradigma deve ser prestado ao mesmo empregador".

Para Delgado (2014, p. 855) "por identidade empresarial entende-se a circunstância de os trabalhadores comparados laborarem para o mesmo empregador".

$\mathrm{O}$ autor ainda sustenta que este requisito é o menos controvertido entre os requisitos da equiparação salarial. No entanto, também sustenta que tal requisito apresenta uma situação relativamente polêmica quanto a sua configuração, quando trata da situação que envolve grupo econômico de empresas.

Assim, existem entendimentos doutrinários e jurisprudenciais de que é perfeitamente possivel o pleito de equiparação salarial para trabalhos prestados a um mesmo grupo 
econômico, sob a sustentação de que as empresas do grupo econômico são consideradas uma única, para efeitos da equiparação salarial.

\section{GRUPOS ECONÔMICOS}

\subsection{EMPREGADOR}

Nos termos do artigo $2^{\circ}$, caput, da CLT empregador define-se como a pessoa física, jurídica ou ente despersonificado que contrata uma pessoa física a prestação de seus serviços, efetuados com pessoalidade, onerosidade, não eventualidade e sob sua subordinação.

Para Leone (2014) para seja considerado empregador basta que uma pessoa física, jurídica ou ente despersonificado explore a energia de trabalho de um empregado.

Conforme o autor a definição da CLT de empregador conduz a algumas reflexões adicionais. Diz o artigo $2^{\circ}$, caput, da CLT que empregador é a empresa, individual ou coletiva, que, assumindo os riscos da atividade econômica, admite, assalaria e dirige a prestação pessoal de serviços, completa o $\S 1^{\circ}$ do mesmo artigo que se equiparam ao empregador para efeitos exclusivos da relação de emprego, os profissionais liberais, as instituições de beneficência, as associações recreativas ou outras instituições sem fins lucrativos, que admitirem trabalhadores como empregados.

Delgado (2014) afirma que o caput celetista é, tecnicamente, falho, assim como o parágrafo primeiro do mesmo artigo, empregador não é a empresa, pois não é ente de sujeito de direitos na ordem jurídica brasileira. Empregador é a pessoa física, jurídica ou ente despersonificado titular da empresa ou estabelecimento.

Assim, a CLT dispõe que o empregador é a empresa, porém, empregador deveria ser a pessoa física ou jurídica.

Não deixa de ser empregador, segundo Martins (2015) aquela atividade organizada que vende bens ou serviços no 
mercado, mas que não tem finalidade de lucro, como as associações, as entidades de beneficência.

Para o autor, empregador também é o ente destituído de personalidade jurídica, ou seja, não é requisito para ser empregador ter personalidade jurídica. Tanto é empregador a sociedade de fato, a sociedade irregular que ainda não tem seus atos constitutivos registrados nas repartições competentes, como a sociedade regularmente inscrita na Junta Comercial ou no Cartório de Registro de Títulos e Documentos. Também será considerado como empregador o condomínio de apartamentos, que não tem personalidade jurídica, mas emprega trabalhadores sob o regime da CLT, conforme Lei 2.757/56.

As entidades que não têm atividade econômica também assumem riscos, sendo consideradas empregadores. Tais pessoas são consideradas pela CLT como empregadoras por equiparação, como as entidades de beneficência ou as associações.

São empregadores a União, Estados-membros, municípios, autarquias, fundações, massa falida, espólio, microempresa. A empresa pública, a sociedade de economia mista e outras entidades que explorem atividade econômica têm obrigações trabalhistas e também são consideradas empregadoras, conforme $\S 1^{\circ}$ do artigo 173 da Constituição.

Martins (2015) acrescenta que a pessoa física que explora individualmente o comércio, também é considerada empregadora. É a chamada empresa individual. A microempresa, também será considerada empregadora, apesar de ter tratamento diferenciado em relação à empresa comum quanto a certas obrigações trabalhistas.

Para o autor, uma das características do empregador é assumir os riscos de sua atividade, tanto os resultados positivos quanto os negativos. Esses riscos, segundo o autor, não podem ser transferidos para o empregado, como ocorre na falência, na concordata e quanto da edição de planos econômicos governamentais. 
Para Martins (2015) é possível conclui que empregador é aquele que tem empregado.

Assim, empregador é aquele que assume os riscos da sua atividade econômica e que contrata mediante salário, dirige, orienta e fiscaliza a atividade laboral.

\subsection{CONFIGURAÇÃO DE GRUPO ECONÔMICO EM- PRESARIAL}

Nos ensinamentos de Süssekind (2010) a criação dos grupos econômicos surgiu da necessidade das empresas de atender aos processos da moderna técnica industrial e ao desenvolvimento do comércio nacional e internacional, pela reunião de capitais de diversas procedências a realização de empreendimentos de grande porte.

Delgado (2014) define grupo econômico para o Direito do Trabalho como a figura resultante da vinculação justrabalhista que se forma entre dois ou mais entes favorecidos direta e indiretamente pelo mesmo contrato de trabalho, em virtude de existir entre esses entes laços de direção ou coordenação em face de atividades industriais, comerciais, financeiras, ou de qualquer outra natureza econômica.

Para o autor o tipo legal do grupo econômico, para fins trabalhistas, está previsto tanto na CLT, como na Lei do Trabalho Rural. Dispõe a CLT, em seu artigo $2^{\circ}, \S 2^{\circ}$ :

$\S 2^{\circ}$ - Sempre que uma ou mais empresas, tendo, embora, cada uma delas, personalidade jurídica própria, estiverem sob a direção, controle ou administração de outra, constituindo grupo industrial, comercial ou de qualquer outra atividade econômica, serão, para os efeitos da relação de emprego, solidariamente responsáveis a empresa principal e cada uma das subordinadas.

Dispõe também o artigo $3^{\circ}, \S 2^{\circ}$, da Lei n. 5.889/73:

$\S 2^{\circ}$ Sempre que uma ou mais empresas, embora tendo cada uma delas personalidade jurídica própria, estiverem sob direção, controle ou administração de outra, ou ainda quando, 
mesmo guardando cada uma sua autonomia, integrem grupo econômico ou financeiro rural, serão responsáveis solidariamente nas obrigações decorrentes da relação de emprego.

Segundo o autor, embora os dois preceitos acima indicados apresentem algumas diferenças ente si, é inquestionável que a leitura de ambos deve ser fazer conjuntamente, por moldarem o mesmo tipo legal, ou seja, o grupo econômico para fins trabalhistas.

Para Martinez (2014) a partir da redação dos preceitos legais, percebe-se que, para fins trabalhistas, o aglutinamento de duas ou mais empresas beneficiárias de um mesmo contrato de emprego produz para todas elas uma situação de subordinação solidária.

Conforme Martins (2015) o grupo econômico de empresas pressupõe a existência de pelo menos duas ou mais empresas que estejam sob comando único.

De acordo com Delgado (2014) o objetivo principal do Direito do Trabalho ao constituir a figura do grupo econômico foi certamente ampliar as possibilidades de garantia do crédito trabalhista, impondo responsabilidade plena por tais créditos às diferentes empresas componentes ao mesmo grupo econômico.

O autor $(2014$, p. 424) defende que "o conceito de grupo econômico aqui examinado é estritamente justrabalhista”. Paro o Autor tal tipo legal não possui efeitos de caráter civil, tributário, comercial ou de qualquer outro ramo do Direito, estando restrito apenas ao Direito do Trabalho e que a figura do grupo econômico justrabalhista não se submete à tipificação legal de grupo econômico que impera em outros seguimentos jurídicos (Direito Comercial, Empresarial e Direito Econômico, por exemplo).

Mesmo entendimento tem Martins (2015) ao declarar que no Direito do Trabalho, verifica-se o grupo econômico de empresas que não pode ser confundido com o Direito Comercial, no sentido do grupo como empregador. 
Süssekind (2010), também, tem o mesmo entendimento ao afirmar que a responsabilidade solidaria das empresas que compõem o grupo econômico, para efeitos da relação de emprego, não depende de formalização, pois o que interessa é a realidade social.

$\mathrm{Na}$ mesma esteira sustenta Delgado (2014) que o grupo econômico de empresas para fins justrabalhistas não necessita das formalidades jurídicas típicas do Direito Econômico ou do Direito Comercial/Empresarial (holdings, consórcios, pools, etc.). Não se exige, tampouco, prova de sua formal institucionalização cartorial. Para o autor pode-se acolher a existência do grupo econômico desde que surjam evidencias que comprovem que estão presentes os elementos da integração interempresarial de que falam os mencionados preceitos da CLT e Lei do Trabalhador Rural.

Colabora Martinez (2012) ao afirmar que o pressuposto de formação do grupo econômico é a concentração econômica, que não depende de qualquer formalização jurídica. $\mathrm{O}$ ato de agregação próprio do grupo econômico não altera a personalidade jurídica de cada uma das empresas que o integram. Tampouco há fusão empresarial. O que existe no grupo econômico é a união de empresas, mantendo suas particularidades, para alcançarem objetivos comuns.

O objetivo da lei, segundo Delgado (2014) é que o sujeito jurídico integrante do grupo econômico para fins justrabalhistas representa essencialmente um ser econômico, uma empresa (expressões sugestivamente enfatizadas pelos dois preceitos legais citados). O caráter e os fins econômicos dos componentes do grupo econômico surgem como elementos qualificadores indispensáveis à caracterização da figura aventada pela ordem jurídica trabalhista.

Para Delgado (2014) e Leite (2014), diante dessa qualidade específica exigida pela ordem jurídica ao integrante do grupo, não têm aptidão para compor a figura do grupo econômico entes que não se caracterizem por atuação econômica, 
que não sejam essencialmente seres econômicos. É o que acontece com o Estado e demais entes estatais, com o empregador doméstico, com entes sem fins lucrativos nominados no $\S 1^{\circ}$ do artigo $2^{\circ}$ da CLT, os chamados empregadores por equiparação, ou seja, os profissionais liberais, instituições de beneficência, associações recreativas, etc.). Assim, a expressão empresa utilizada pela CLT, ao se referir ao empregador (art. $2^{\circ}$ ), ganha notável funcionalidade no que diz respeito a caracterização da figura do grupo econômico justrabalhista.

É possivel concluir que a figura do grupo econômico para o direito do trabalho surgiu da necessidade de otimização de recursos pelas empresas. As empresas foram criando outras empresas, ou se juntando a outras para aperfeiçoar recursos e mão de obra. Para o direito do trabalho não é necessário a formalização jurídica do grupo econômico, basta apenas o aparente nexo relacional que se estabelece entre as empresas para que possa ser considerado a caracterização do grupo econômico.

\subsection{A HIERARQUIZAÇÃO NO GRUPO ECONÔMICO DE EMPRESAS}

Outro ponto de estudo sobre os grupos econômicos é a hierarquização que deve, ou não, existir entre as empresas componentes do grupo econômico.

Para Delgado (2014), outro requisito para a existência de um grupo econômico justrabalhista é o nexo relacional existente entre as empresas integrantes do grupo. Entendo o autor que existe divergência jurisprudencial e doutrinária a esse respeito. Alguns restringem a configuração do grupo econômico a nexo de efetiva direção hierárquica entre as empresas componentes do grupo, o que Martinez (2012) chama de modo hierarquizado; para outros, a simples relação de coordenação entres as empresas do grupo gera o nexo de relacional exigido pela ordem jurídica, o que Moura (2014) denomina de grupo econômico horizontal. 
Ainda, defende (2014) a vertente de que deve haver relação de coordenação entre as empresas do grupo, entendimento do jurista Octavio Bueno Magno. Para o jurista deve haver uma relação de dominação interempresarial, através da direção, controle ou administração da empresa principal sobre as filiadas, e o texto literal celetista aproxima-se dessa leitura, uma vez que, de fato, a CLT utiliza-se da expressão sob direção, controle ou administração de outra.

Mesmo entendimento tem Martins (2015), para o Autor a relação que deve existir entre as empresas do grupo econômico é de dominação, evidenciando a existência de uma empresa principal, que é a controladora, e as empresas controladas. A denominação é representada pela direção, controle ou administração.

O autor defende que o requisito principal é o controle de uma empresa sobre a outra, que nada mais é que a possibilidade de uma empresa exercer influência dominante sobre a outra. O controle é exercido pelo fato de uma empresa deter a maioria das ações de outra, ou mesmo que tenha a minoria das ações, mas detendo o poder pelo fato de haver dispersão na titularidade das ações entre várias pessoas. A caracterização do controle deve ser demonstrada pelo fato de existir empregados comuns entre uma ou mais empresas, assim como acionistas comuns, mesmo que sejam de uma mesma família, administradores ou diretores comuns, quando as empresas possuem o mesmo local ou a mesma finalidade econômica.

Acrescenta o autor que o controle é um dos fundamentos da direção, que representa a sua efetivação e pode ser dividido em poder diretivo, de fiscalização e disciplinar.

A administração decorre da organização do grupo, do poder de que uma empresa se investe em relação a outra, em relação à orientação e ingerência de seus órgãos. A partir desse entendimento, se uma empresa é arrentada a outra, existe a possibilidade de se admitir a existência do grupo, pois ambas são administradas por uma só pessoa. 
Ainda segundo Martins (2015), a existência de um grupo de empresas é visualizada de forma melhor quando existe uma empresa-mãe e empresas-filhas, caracterizando o controle de uma sobre a outra, como ocorre com a holding ${ }^{1}$.

A influência dominante de uma empresa, segundo Martinez (2012) é entendida como fundamental para a aplicabilidade de norma contida no $\S 2^{\circ}$ do artigo $2^{\circ}$ da CLT. Esse entendimento está fundamentado no argumento de que o grupo econômico trabalhista somente se formaria de modo hierarquizado.

No entanto para o autor a publicação da Lei $n^{\circ} 5.889 / 73$ em seu artigo $3^{\circ} \S 2^{\circ}$ e a declaração Constitucional de igualdade entre trabalhadores urbanos e rurais (caput do art. $7^{\circ}$ ), fazem surgir outro entendimento, que não apenas a hierarquização caracterizaria o grupo econômico, mas também situações em que cada componente preservasse sua autonomia, ou seja, é dispensável a existência de uma relação de domínio para a caracterização do grupo econômico trabalhista, surgindo assim o grupo econômico horizontal.

Para Delgado (2014), em contraponto ao texto literal celetista, que parece concordar com a tese do nexo relacional hierárquico (artigo $2^{\circ}, \S 2^{\circ}, \mathrm{CLT}$ ), o texto literal do artigo $3^{\circ}$, $\S 2^{\circ}$ da Lei 5.889/73 favorece nitidamente a tese do nexo relacional de simples coordenação. "[...] estiverem sob direção, controle ou administração de outra, ou ainda quando, mesmo guardando cada uma sua autonomia [...]" (grifos acrescidos)

A conclusão que se chega por interpretação do preceito legal é que não é necessário o controle de uma empresa mãe, nem subordinação a ela para caracterização do grupo econômico, afirma Moura (2014).

\footnotetext{
Holding é uma sociedade gestora de participações sociais que administra conglomerados de um determinado grupo. Trata-se de uma empresa que possui a maioria das ações de outras empresas e que detém o controle de sua administração e políticas empresariais. 
Segundo Delgado (2014) a vertente que considera uma simples relação de coordenação interempresarial é suficiente para atender o sentido essencial almejado pela ordem justrabalhista. Segundo o autor, a própria informalidade conferida pelo Direito do Trabalho à noção de grupo econômico de empresas seria incompativel com a ideia de se aceitar a presença do grupo somente a partir da existência de uma relação hierárquica e assimétrica entre os seus componentes. Assim, se a intenção principal do ramo justrabalhista foi ampliar a garantia de créditos salariais, não há razão para reduzir a figura do grupo econômico em função de um aspecto que representa caráter irrelevante do ponto de vista dos contratos empregatícios firmados.

Mesmo entendimento tem Nascimento (2011) e afirma que basta uma relação de coordenação entre as diversas empresas sem que exista uma empresa controladora, o que representa um critério mais acetado em relação à garantia das verbas trabalhistas.

Para Delgado (2014) ainda que se insista na tese do nexo relacional hierárquico entre as empresas, está pacificado que é indiferente que tal controle venha ser exercido por pessoa jurídica ou física.

Mesmo entendimento é observado abaixo:

[...] pelo fato de estar o controle das empresas em mãos de uma ou algumas pessoas físicas detentoras do número suficiente de ações para que se estabeleça, não ficara descaracterizado o grupo, uma vez que a unidade de comando econômico existirá da mesma forma que ocorre quando a propriedade das ações é de uma empresa (NASCIMENTO, 1989, p. 141 e 142 APUD DELGADO, 2014, p. 427).

A formação do grupo econômico de empresas pressupõe para alguns autores a existência de uma empresa-mãe e empresas-filhas, onde aquela interfere hierarquicamente nas atividades destas. Para outros autores a simples relação de 
coordenação entre as empresas do grupo gera o nexo relacional capaz de caracterizar a formação do grupo de empresas horizontal. Assim, tanto faz para o pleito da equiparação salarial a maneira que se reconhece o grupo econômico de empresas, se hierarquizado ou horizontal, o que realmente importa é a garantia dos créditos salarias.

\subsection{A SOLIDARIEDADE (ATIVA/PASSIVA) ENTRE AS EMPRESAS DO GRUPO ECONÔMICO}

Com a formação do grupo econômico de empresas surge a responsabilidade que cada empresa tem em relação aos empregados e aos créditos trabalhistas.

A figura justrabalhista do grupo econômico, segundo Delgado (2014) surgiu com o propósito de ampliação da garantia dos créditos trabalhistas em favor do empregado, sendo esse seu real objetivo e efeito, contudo tal figura não é isenta de debates e resistências entre juristas que atribuem ao grupo econômico de empresas dois efeitos: a solidariedade exclusivamente passiva e a solidariedade passiva e ativa.

A solidariedade não se presume, pois decorre da lei ou a vontade dos contratantes (art. 265 do CC). Há solidariedade quando na mesma obrigação concorre mais de um credor (solidariedade ativa) ou mais de um devedor (solidariedade passiva), cada um com direito, ou obrigação, à divida toda (art. 264 do CC) (MOURA, 2014, p. 182)

Bonfim (2015) ensina que a solidariedade ativa é a existente entre credores e a passiva entre codevedores, regra contida no atual Código Civil.

Delegado (2014) esclarece que o efeito jurídico clássico e incontroverso da figura justrabalhista do grupo econômico é a imposição de solidariedade passiva entre as empresas componentes do grupo, diante dos créditos trabalhistas derivados de contrato de trabalho firmado por uma ou algumas dessas entidades. 
Moura (2014), afirma que a doutrina trabalhista, majoritariamente, reconhece na rega do artigo $2^{\circ}, \S 2^{\circ}$, CLT a figura da solidariedade passiva, em que todas as empresas que integram o grupo econômico respondem, igualmente, por qualquer obrigação dos empregados das empresas do grupo.

Leite (2014) esclarece que diante da solidariedade passiva o empregado poderá ajuizar reclamação trabalhista em face de um ou de todos os devedores pleiteando, total ou parcialmente, a divida em comum.

Moura (2014) também ensina que a doutrina identifica, ainda que de forma minoritária, a possibilidade de cada empregador do grupo econômico exigir a prestação de serviços de qualquer empregado do grupo, independente de que com qual empresas do grupo se tenha contrato de trabalho. Nesta hipótese todas as empresas são potencialmente credoras da mão de obra de qualquer destes empregados, formando um único empregador, a chamada tese da solidariedade ativa.

Para Delgado (2014) a jurisprudência, com a edição da Súmula 129 do TST, já formou entendimento da possibilidade do empregador único. Diz a Súmula:

\footnotetext{
Súmula $\mathrm{n}^{\circ} 129$ do TST

CONTRATO DE TRABALHO. GRUPO ECONÔMICO (mantida) Res. $121 / 2003$, DJ 19, 20 e 21.11 .2003

A prestação de serviços a mais de uma empresa do mesmo grupo econômico, durante a mesma jornada de trabalho, não caracteriza a coexistência de mais de um contrato de trabalho, salvo ajuste em contrário.
}

Para Martinez (2012) a instrução jurisprudencial deixa claro o reconhecimento da solidariedade ativa, em que todas ou algumas empresas integrantes do mesmo grupo econômico podem se aproveitar do trabalho prestado por um mesmo empregado.

Segundo Silva (2010), a prestação de serviço, simultaneamente, a várias empresas coligadas, sem que com isso 
gere direito a vários contratos de trabalho, é dado seguro da caracterização do empregador único.

Para essa segunda vertente, a solidariedade das empresas componentes do grupo não existe apenas perante as obrigações trabalhistas que lhes decorrem dos contatos empregatícios (solidariedade passiva), mas também perante os direitos e prerrogativas laborativas que lhes favorecem em função desses mesmos contratos (solidariedade ativa). Todos os membros do grupo seriam, pois ao mesmo tempo, empregadores e não somente garantidores de créditos derivados de um contrato de emprego. Em outras palavras, configurado o grupo econômico, todas as empresas integrantes de tal grupo, consolidariam empregador único em face dos contratos de trabalho firmados por todas as empresas individualmente.

A respeito da tese empregador único, da solidariedade dual e combinada, solidariedade ao mesmo tempo ativa e passiva, argumenta Octavio Bueno Magano:

A apontada ideia de empregador único corresponde à concepção do empregador real, contraposto ao empregador aparente, consoante a qual a existência daquele fica geralmente encoberta pelo véu da personalidade jurídica atribuída a cada uma das empresas do grupo, ressurgindo, porém, toda vez que se levante o véu, lifting the corporate veil, para satisfazer tal ou qual interesse, como o da representação de trabalhadores no âmbito do grupo; o da negociação coletiva ao nível do grupo; o da garantia de condições uniformes de trabalho; o da transferência de trabalhadores; o da soma de períodos de serviços prestados a mais de uma empesa; o da garantia de reintegração do trabalhador em empresa matriz, quando o seu contrato se rescinde junto à filial; o da distribuição de lucros, etc. (DELGADO, 2014 p. 429)

O acolhimento da tese da solidariedade ativa gera alguns efeitos importantes em relação ao contrato de trabalho do empregado perante o grupo econômico, tais como: a contagem do tempo de serviço prestado sucessivamente às diversas 
empresas do grupo; possibilidade de veiculação; pagamento de um único salário ao empregado por jornada normal, ainda que o empregado esteja prestando serviços concomitantemente a distintas empresas do grupo; extensão do poder de direção empresarial para as demais empresas do grupo; a transferência para qualquer empresa integrante do grupo econômico, a transferência de localidade deverá respeitar a real necessidade do serviço de acordo com a Súmula 43 TST e as demais regras do artigo 469 da CLT, conforme ensina Delegado (2014).

Para Martinez (2012) a solidariedade do grupo econômico é bifrontal ou dual (ativa e passiva). Será passiva porque todas as empresas integrantes do grupo econômico respondem juntas pelas obrigações assumidas diante de seus empregados. Será também ativa porque o grupo econômico pode exigir do empregado o cumprimento da prestação dos serviços em favor de qualquer uma das empresas que compõem o grupo econômico. Porém, é necessário que exista ajuste contatual neste sentido. $\mathrm{O}$ autor defende que por regra contida no caput do artigo 468 da CLT $^{2}$ a solidariedade ativa só será aceita se no momento da admissão o empregador (grupo econômico) e empregado, ajustarem que os serviços serão prestados para todas as empresas integrantes do grupo econômico.

Bonfim (2015) exemplifica que na solidariedade ativa o empregado da empresa A tem direito, por exemplo, ao estatuto interno da empresa B as normas coletivas da empresa $\mathrm{C}$, todas do mesmo grupo, sempre que mais benéficas que aquelas existentes na empresa empregadora.

2 Art. 468 - Nos contratos individuais de trabalho só é lícita a alteração das respectivas condições por mútuo consentimento, e ainda assim desde que não resultem, direta ou indiretamente, prejuízos ao empregado, sob pena de nulidade da cláusula infringente desta garantia.

Parágrafo único - Não se considera alteração unilateral a determinação do empregador para que o respectivo empregado reverta ao cargo efetivo, anteriormente ocupado, deixando o exercício de função de confiança. 
Martins (2015) conclui que a teoria da solidariedade ativa entende que o empregador é um só (o grupo), o empegado que trabalha para uma empresa do conglomerado trabalha, na verdade, para todo o grupo econômico.

A solidariedade passiva entende que todas as empresas que compõe o grupo econômico respondem, igualmente, por qualquer obrigação dos empregados das empresas do grupo. Já a solidariedade ativa entente que o empregado de uma empresa do grupo é empregado de todo o grupo, e este pode aproveitar a força de trabalho em proveito de todo o conglomerado, o que gera um único contrato de trabalho. Surge então a solidariedade dual: a obrigação dos créditos trabalhistas por todas as empresas do grupo e o aproveitamento da força de trabalho por todo o grupo.

Este entendimento é fundamental para o pleito da equiparação salarial nos grupos econômicos, pois se todas as empresas que compõe o grupo econômico podem aproveitar a força de trabalho de um empregado é lógico pensar que um empregado pode pleitear equiparação salarial em relação a um paradigma de outra empresa que compõe o grupo econômico.

\section{EQUIPARAÇÃO SALARIAL NOS GRUPOS ECONÔMICOS}

Analisaremos os pontos de encontro e desencontro sobre a aplicação da equiparação salarial para empregados de empresas integrantes de um mesmo grupo econômico através de uma análise doutrinaria e jurisprudencial de recentes decisões sobre o pleito da equiparação salarial

\subsection{ANÁliSE DOUTRINÁRIA}

Para Barros (2005) é possivel o pedido de equiparação salarial entre empregados de empresas integrantes de um mesmo grupo econômico. Para a autora o conceito de grupo econômico previsto no artigo $2^{\circ} \S 2^{\circ}$ da CLT considera solidariamente responsável a empresa principal a cada uma das empresas integrantes e subordinadas, para efeito da relação de 
emprego, sendo que um dos efeitos da relação de emprego é a possibilidade da equiparação salarial, pois o legislador não fez nenhuma ressalva quando definiu a responsabilidade solidária, assim, deve-se respeitar o princípio da igualdade salarial.

Martins (2015) também é a favor da equiparação salarial no grupo econômico de empresas. Para o autor a consideração do grupo econômico de empresas como empregador único também repercute no instituto da equiparação salarial. Martins (2015, p. 349) cita decisão do pleno do TST que decidiu da mesma forma: "comprovadas a existência de grupo econômico e a identidade de funções e produtividade, a disparidade salarial ofende o art. 461 da CLT" (E-RR 3.055/76, Rel. Min. Alves Almeida, j. 30-8-78, DJU 1º-9-78, p. 6.495).

Conforme o autor (2015), a única limitação à aplicação da equiparação salarial entre empregados de empresas integrantes do mesmo grupo econômico está na diferença de categoria econômica entre as empresas integrantes do grupo. Para o autor é necessário que o empregado e o paradigma prestem serviços a empresas que tenham a mesma atividade econômica, vinculadas ao mesmo sindicato, para a aplicação da equiparação salarial. Assim, atendidos os demais requisitos previstos no artigo 461 da CLT a equiparação salarial será devida.

Para Delgado (2014) o reconhecimento da tese da solidariedade dual (passiva e ativa) para o grupo de empresas o torna em empregador único, sendo possivel, assim, ser reconhecido a incidência da equiparão salarial entre empregados de empresas integrantes de um mesmo grupo econômico, desde que presente os demais requisitos do instituto da equiparação salarial previstos no artigo 461 da CLT.

Süssekind (2010) tem posicionamento contrário, não sendo possível a aplicação da equiparação salarial a empregados de empresas integrantes de um mesmo grupo econômico. Defende o autor que a solidariedade prevista no $\S 2^{\circ}$ do artigo $2^{\circ}$ da CLT não implica a uniformização das normas 
regulamentares, bem como dos respectivos quadros de pessoal ou tabelas de salário de cada empresa. Cada empresa exerce individualmente seu poder diretivo de organizar suas normas e ajustes salariais, mesmo pertencendo a um grupo econômico. O autor adverte que somente na cessão de um empregado de uma empresa para outra dentro de um grupo econômico é possível a equiparação salarial, pois neste caso o empregador ser torna comum.

$\mathrm{O}$ autor ainda defende que a solidariedade no campo social-trabalhista está limitada a relação de emprego e não se estende a equiparações salariais.

Saad (2004) também afirma que não é possivel o reconhecimento da equiparação salarial entre empregados de empresas integrantes de um mesmo grupo econômico. Para o autor o requisito mesmo empregador deve receber interpretação restritiva, sendo reconhecida apenas a empresa para qual se presta serviços como mesmo empregador, não se estendendo tal interpretação para o grupo econômico de empresas. O autor defende que cada empresa, mesmo pertencendo a um grupo econômico, tem suas particularidades e rentabilidades que refletem nos pagamentos dos empegados, o que torna impossivel uma mesma política salarial para todo o grupo econômico.

É possivel perceber que não há uniformidade na doutrina quanto a aplicação da equiparação salarial aos empregados de empresas distintas pertencentes a um mesmo grupo econômico. Para alguns autores é perfeitamente aceitável o reconhecimento do empregador único, do mesmo modo que para outros a tese é impossivel, pois cada empresa, mesmo pertencendo a um grupo econômico, guarda sua personalidade jurídica e faturamento o que impossibilita tal reconhecimento.

\subsection{ANÁLISE JURISPRUDENCIAL}

Também não há uniformidade na doutrina quanto a aplicação da equiparação salarial aos empregados de empresas distintas pertencentes a um mesmo grupo econômico 
Inicialmente será analisado o processo $R R n^{\circ} 30$ 24.2010.5.02.0254, o processo trata-se de um pedido de um maquinista da Ferronorte Ferrovias Norte Brasil S/A que pretende a equiparação salarial com ocupantes da mesma função de outras empresas do grupo América Latina Logística Ltda. (ALL).

Na reclamação trabalhista, o maquinista alegou a existência de uma diferença salarial de cerca de $45 \%$ (quarenta e cinco por cento) entre ele e colegas contratados pela empresa Portofer Transporte Ferroviário S/C Ltda., integrantes do mesmo grupo.

O grupo Brasil Ferrovias é composto das empresas Ferronorte, Protofer, Ferrovia Novoeste e Ferrovias Bandeirantes (Ferroban). Em 2006, a Brasil Ferrovias fundiu-se à ALL. O pleito de equiparação foi indeferido pela $4^{a}$ Vara do Trabalho de Cubatão (SP). Segundo o juiz, a solidariedade, prevista no artigo $2^{\circ}, \S 2^{\circ}$ da CLT, entre empresas do mesmo grupo econômico não alcançaria o aspecto salarial. "Cada uma das empresas do grupo tem personalidade jurídica própria e se obrigam apenas ao ajustado com seus empregados em contratos ou em norma coletiva", afirma a sentença.

Proposto recurso, o TRT da $2^{a}$ Região negou o seu provimento, com fundamento semelhante ao juízo a quo. Para o órgão Regional, "embora a formação do grupo econômico implique várias consequências, não tem o condão de estender os direitos dos trabalhadores de uma empresa às outras, pois a relação empregatícia decorre do ajuste entre o empregado e a empresa individualmente considerada, e não entre o empregado e o grupo econômico tomado em sua unicidade".

O trabalhador inconformado recorreu ao TST. Em seu recurso de revista, julgado pela $3^{\text {a }}$ Turma, defendeu a tese do empregador único, sob a argumentação de que a Súmula $n^{\circ}$ 129 do TST determina que o trabalho a mais de uma empresa ao mesmo grupo econômico não implica o reconhecimento de mais de mais um contrato, alegando ainda que a Ferronorte 
admitiu a identidade de função e não provou fatos que impedissem o reconhecimento do direito.

O relator, ministro Maurício Godinho Delgado, deu razão parcial ao maquinista reconhecendo a figura do empregador único, nos seguintes moldes:

AGRAVO DE INSTRUMENTO. RECURSO DE REVISTA. EQUIPARAÇÃO SALARIAL. GRUPO ECONÔMICO. EMPRESAS DISTINTAS. SÚMULA 129/TST. POSSIBILIDADE. Demonstrado no agravo de instrumento que o recurso de revista preenchia os requisitos do art. 896 da CLT, dá-se provimento ao agravo de instrumento, para melhor análise da arguição de contrariedade à Súmula 129/TST suscitada no recurso de revista. Agravo de instrumento provido. RECURSO DE REVISTA. EQUIPARAÇÃO SALARIAL. GRUPO ECONÔMICO. EMPRESAS DISTINTAS. SÚMULA 129/TST. POSSIBILIDADE. O grupo econômico enseja solidariedade ativa e passiva (solidariedade dual), entre os seus integrantes, formando o chamado empregador único. Tal entendimento está sedimentado na Súmula 129 do TST, que preceitua: -A prestação de serviços a mais de uma empresa do mesmo grupo econômico, durante a mesma jornada de trabalho, não caracteriza a coexistência de mais de um contrato de trabalho, salvo ajuste em contrário. - Desse modo, é viável falar-se em equiparação entre empregados contratados por diferentes empresas do grupo, desde que presentes os demais requisitos da figura do art. 461 da CLT. Contudo, no caso vertente, verifica-se que o Juízo de $1^{\circ}$ Grau não analisou o caso concreto quanto à existência dos demais requisitos da equiparação salarial pretendida, quais sejam, identidade de função exercida, identidade de localidade de exercício das funções e simultaneidade nesse exercício, construídos pela comparação entre as situações empregatícias reais vivenciadas pelo Reclamante e paradigmas por ele indicados. Satisfez-se com a tese de que não havia idêntico empregador -- porém em manifesto desrespeito à Súmula 129 do TST. Nesse contexto, considerando-se os limites de cognição em instância extraordinária e diante da possibilidade de incidência da figura da equiparação salarial envolvendo empregadores vinculados a distintas empresas do mesmo grupo, a teor da Súmula 129/TST, torna-se necessário o retorno dos autos ao Juízo de $1^{\circ}$ Grau, a fim de que analise os requisitos ense- 


\section{EQUIPARAÇÃO SALARIAL ENTRE EMPREGADOS \\ DE UM MESMO GRUPO ECONÔMICO}

jadores da equiparação salarial pretendida entre o Reclamante e os paradigmas. Recurso de revista conhecido e parcialmente provido. (RR - 30-24.2010.5.02.0254. Relator Ministro: Mauricio Godinho Delgado, Data de Julgamento: 17/10/2012, $3^{\text {a }}$ Turma, Data de Publicação: DEJT 19/10/2012).

A $3^{\text {a }}$ Turma do TST determinou a remessa do processo, ao juízo de primeiro grau, no qual o pedido havia sido rejeitado. A Turma reconheceu a possibilidade de incidência da equiparação envolvendo empregados vinculados a empresas distintas do mesmo grupo.

Mesmo entendimento apresentam os próximos dois julgados. O primeiro, do Tribunal Regional do Trabalho de Santa Catarina demonstra que estando comprovados os requisitos da equiparação salarial, o fato dos empregados serem de empresas distintas, porém pertencerem ao mesmo grupo econômico, não é impedimento para a equiparação salarial, da mesma forma que não há impedimento se as empresas integrantes do grupo econômico estiverem em localidades distintas, mas presentes no mesmo município:

Equiparação salarial - Grupo econômico - Desde que comprovada a identidade de funções, não obsta o pleito de equiparação salarial a prestação de serviços a empresa que, embora diversa da empregadora do paradigma, pertence ao mesmo grupo econômico, porquanto aquelas são, para efeitos do contrato de trabalho, consideradas como um único empregador. A melhor interpretação do art. $2^{\circ}, \S 2^{\circ}$, da CLT, é a que considera que, no âmbito da relação de emprego o grupo econômico afigura-se como empregador único, abarcando todas as empresas que o compõem. Assim, é irrelevante a circunstância de prestarem serviços, reclamante e paradigma, a empresas diversas do mesmo conglomerado. Também não impede o pleito equiparatório o fato de o paradigma trabalhar em outra unidade fabril, desde que ambas situem-se no mesmo município (Súmula $\mathrm{n}^{\circ} 6, \mathrm{X}$, do TST). (TRT-12 a Região - RO 06334-2009-050-12-00-4 - $6^{a}$ C. - Rel. José Ernesto Manzi - DJe 31.05.2011). 
O segundo julgado pertence ao Tribunal Regional do Trabalho de São Paulo, que remete a aplicação da Súmula 129 do TST, a qual considera como único o contrato de trabalho prestado a empregadores diferentes, dentro da mesma jornada de trabalho, mas pertencentes ao mesmo grupo econômico, sendo considerado para os efeitos da relação de trabalho único empregador:

Equiparação salarial - Empregados de empresas distintas de um mesmo grupo econômico - Cabimento - Uma vez que a Súmula $n^{\circ} 129$ do TST determina que a prestação de serviços, no mesmo horário de trabalho, a mais de uma empresa do mesmo grupo econômico, não configura novo contrato de trabalho, a conclusão lógica que daí se extrai é que o grupo econômico se apresenta como empregador único, sendo possível a equiparação salarial entre empregados de empresas do mesmo grupo. Recurso Ordinário do reclamante provido, no aspecto. (TRT-02a Região - RO 00075001820105020251 (00075201025102009) (20110717591) - 14 ${ }^{\text {a }}$ Turma - Rel. Juiz Davi Furtado Meirelles - DOE/SP 08.06.2011)

As decisões sobre a equiparação salarial entre empregados de empesas integrantes de um mesmo grupo econômico não são pacíficas. Há inúmeros julgados que não reconhecem como empregador único o grupo econômico de empresas, é o caso do próximo julgado extraído da $3^{\circ}$ Turma do TST:

Recurso de revista - Equiparação salarial e grupo econômico - A controvérsia em torno da equiparação salarial foi dirimida pela Corte Regional em conformidade com o entendimento desta $3^{\text {a }}$ Turma de que a interpretação literal do caput do art. 461 da CLT afasta a equiparação salarial entre empregados de empresas distintas, embora integrantes do mesmo grupo econômico (Processo RR-120140-81.2007.5.15.0129, 3a Turma, Rel. Min. Alberto Luiz Bresciani de Fontan Pereira, publicado em 17/09/2010), em que pese ressalvas deste Relator. Precedentes da SBDI. Recurso de revista não conhecido. (TST - RR 160400-06.2007.5.15.0129 - Rel. Min. Horácio Raymundo de Senna Pires - DJe 02.09.2011 - pág. 1115) 


\section{EQUIPARAÇ̃̃O SALARIAL ENTRE EMPREGADOS \\ DE UM MESMO GRUPO ECONÔMICO}

Mesmo entendimento apresenta o próximo julgado do Tribunal Regional do Trabalho do Rio de Janeiro em não reconhecer a equiparação salarial entre empregados de empresas integrantes de um mesmo grupo econômico, para o julgado as empresas que integram o grupo têm personalidades jurídicas próprias e administração distinta, motivos para não reconhecer o pedido de equiparação salarial;

EQUIPARAÇÃO SALARIAL. GRUPO ECONÔMICO. Não há equiparação salarial entre empregados de empresas diversas de um mesmo grupo econômico quando os empregadores são distintos, com personalidades jurídicas próprias, com quadros de empregados diferentes, bem como autônomos administrativamente. Circunstâncias que tornam impossivel a presença de identidade funcional, requisito exigido pela lei para o reconhecimento da equiparação postulada. (TRT-1 - RO: 00017250520125010049 RJ, Relator: Gustavo Tadeu Alkmim, Data de Julgamento: 25/03/2014, Primeira Turma, Data de Publicação: 01/04/2014)

A $5^{\text {a }}$ Turma do TST tem o mesmo posicionamento e em sua decisão, diz que não existe equiparação salarial diante do grupo econômico de empresas, pois não existe o requisito vital para a sua caracterização: o mesmo empregador:

RECURSO DE REVISTA.EQUIPARAÇÃO SALARIAL - GRUPO ECONÔMICO. O fato de reclamante e paradigma trabalharem para empresas distintas, ainda que pertencentes ao mesmo grupo econômico, afasta a possibilidade de equiparação salarial, ante a ausência de requisito vital - mesmo empregador. Recurso de Revista parcialmente conhecido e provido. (TST - RR: 7347992020015175555 734799-20.2001.5.17.5555, Relator: Darcy Carlos Mahle, Data de Julgamento: 14/08/2002, $5^{\text {a }}$ Turma, Data de Publicação: DJ 30/08/2002.)

É possível concluir nesta breve análise jurisprudencial, assim como na análise doutrinária, que não existe posicionamento pacífico quanto o reconhecimento da equiparação salarial entre empregados de empresas integrantes de 
um mesmo grupo econômico. O que se percebe é que a atual posição do TST é mais restritiva, não considerando a aplicação da equiparação salarial nos grupos econômico. Já nos TRTs, os entendimentos são mais amplos em reconhecer os grupos econômicos como empregador único para a aplicação da equiparação salarial.

\section{CONSIDERAÇÕES FINAIS}

O trabalho teve como objetivo buscar a possibilidade, ou não, da aplicação da equiparação salarial entre empregados de empresas distintas, porém de um mesmo grupo econômico. Essa busca teve início na análise dos princípios do direito do trabalho. Inicialmente foi estudado o princípio da proteção, o qual se desdobra em outros importantes princípios: princípio da norma mais favorável, princípio da condição mais benéfica e princípio in dubio pro operario, que garantem ao trabalhador, que é considerado o hipossuficiente da relação laboral, uma teia de proteção, para equilíbrio do contrato de trabalho.

O princípio da primazia da realidade também foi objeto de estudo, o princípio visa proteger a verdade real dos fatos em relação ao que foi pactuado no contrato formal, assim, para o princípio, pouco importa o que está previsto no contrato de trabalho se for diferente a realidade dos fatos. Esse princípio apresenta grande importância para o tema equiparação salarial e a caracterização do grupo econômico.

$O$ instituto da equiparação salarial também foi estudado no presente trabalho. Com ênfase no requisito mesmo empregador.

O grupo econômico de empresas foi o objeto de maior estudo do trabalho. Pode-se perceber que o tema guarda grande divergência na doutrina e jurisprudência. O que não é controverso é que a figura do grupo econômico para fins trabalhista não necessita de formalidades para sua configuração, basta que empresas se unam sob uma mesma organização e cooperação para que fique caracterizada a sua existência. 
Sob esse tema alguns doutrinadores entendem que a subordinação existente entre as empresas que compõem o grupo econômico é de subordinação/ hierarquização, nesta hipótese existe a figura de uma empresa-mãe e empresas filhas, onde aquela dirige e controla as ações destas, outros doutrinadores por sua vez entendem que basta uma simples coordenação para se evidencie a figura do grupo econômico.

Com a configuração do grupo econômico de empresas surge a solidariedade para os efeitos da relação de trabalho, que para alguns doutrinadores é somente passiva e para outros passiva e ativa (dual).

Será passiva quando todas as empresas do grupo respondem, tão somente, pelos salários de seus empregados. Será ativa quando todas as empresas puderem ter a faculdade de requerer a prestação de serviços dos empregados que compõem o grupo econômico, sem que com isso exista a necessidade de um novo contrato de trabalho, é o que a doutrina e a jurisprudência denominam de empregador único.

Como foi demonstrado há divergência na doutrina quanto na jurisprudência a respeito da aceitação da figura do empregador único para fins da aplicação da equiparação salarial para empregados de empresas distintas pertencentes ao mesmo grupo econômico. $\mathrm{Na}$ análise jurisprudencial ficou demonstrado que o tema é mais aceito nos tribunais regionais, porém no TST é mais resistente a tese.

Uma mudança no entendimento do TST é de suma importância para a proteção dos direitos trabalhistas em nossa sociedade, tendo em vista a grande mudança social e econômica a qual vivenciamos nos dias atuais. A globalização e a competitividade das empresas fizeram nascer um novo empregador, o grupo econômico, que deve respeitar os direitos trabalhistas em especial o instituto da equiparação salarial.

Porém, deve existir uma justa medida. É justa a equiparação salarial entre empresas que executem a mesma atividade, ou seja, mesmo enquadramento sindical, como 
defende Sergio Pinto Martins, mas não parece ser coerente o reconhecimento do pedido de equiparação salarial entre empresas que exercem atividades completamente distintas, como por exemplo, um hospital e uma metalúrgica, pois embora as empresas pertençam ao mesmo grupo econômico a própria atividade dos empregados se torna distinta em razão da atividade empresarial.

O tema ainda será objeto de muito estudo pela doutrina e jurisprudência, a fim de se chegar a um entendimento pacífico que estabeleça harmonia entre as partes. Entendimento que respeite a força de trabalho ao mesmo tempo em que contribua com o desenvolvimento econômico das empresas.

\section{REFERENCIAS}

BARRos, Alice Monteiro de. Curso de direito do trabalho. 10. ed. São Paulo: LTr, 2016.

BOMfIM, Volia. Direito do Trabalho. $11 .^{\mathrm{a}}$ ed. ver. e atual. Rio de Janeiro: Forense, 2015.

CARRION, Valentin. Comentários à Consolidação das Leis do Trabalho-Legislação Complementar, Jurisprudência. - 39. ed. São Paulo: Saraiva, 2014. DELGADO, Mauricio Godinho. Curso de Direito do Trabalho. 15. ed. São Paulo: LTr, 2016.

LEITE, Carlos Henrique Bezerra. Curso de Direito do Trabalho. 7. ed. rev., ampl. e atual. São Paulo: Saraiva, 2016.

MARTINEZ, Luciano. Curso de direito do trabalho: relações individuais, sindicais e coletivas do trabalho. 3. ed. São Paulo: Saraiva, 2012.

MARTINS, Sergio Pinto. Comentários às Súmulas do TST. 14. ed. São Paulo: Atlas, 2014.

Direito do Trabalho. 31. ed. São Paulo: Atlas, 2015.

MARTINS FILHO, Ives Gandra da Silva. Manual esquematizado de direito e processo do trabalho. 15. ed. rev. e atual. São Paulo: Saraiva, 2007. MOURA, Marcelo. Curso de direito do trabalho. São Paulo: Saraiva, 2012. NASCIMENTO, Amauri Mascaro. Curso de direito do trabalho: história e teoria geral do direito do trabalho: relações individuais e coletivas do trabalho. 26. ed. São Paulo: Saraiva, 2011.

PEREIRA, Leone. Direito do Trabalho. 4 ed. rev. e atual. São Paulo: Revista dos Tribunais, 2014.

PLÁ RODRIGUES, Américo. Princípios do direito do trabalho. 3. ed. atual. São Paulo: LTr, 2000.

SAAD, Eduardo Gabriel. Consolidação das Leis do Trabalho Comentada. 37. ed. São Paulo: LTr, 2004. 


\section{EQUIPARAÇÃO SALARIAL ENTRE EMPREGADOS \\ DE UM MESMO GRUPO ECONÔMICO}

SILVA, Homero Batista Mateus da. Curso de direito do trabalho aplicado, Volume 5: Remuneração. 2. ed. - São Paulo: Revista dos Tribunais, 2015. SÜSSEKIND, Arnaldo. Curso de Direito do Trabalho. $3^{\text {a }}$. ed. ver. e atualiz. Rio de Janeiro: Renovar, 2010. 